\title{
Learning curve of sutureless transconjunctival 20-gauge vitrectomy
}

This article was published in the following Dove Press journal:

Clinical Ophthalmology

17 July 2014

Number of times this article has been viewed

\author{
Gilbert WS Simanjuntak ${ }^{1,2}$ \\ Arief S Kartasasmita ${ }^{3,4}$ \\ Ilias Georgalas ${ }^{5}$ \\ Eustratios V Gotzaridis ${ }^{6}$ \\ 'Department of Ophthalmology, \\ Faculty of Medicine, Christian \\ University of Indonesia, Jakarta, \\ ${ }^{2}$ Cikini Eye Institute, Cikini CCl \\ Hospital, Jakarta, ${ }^{3}$ Department \\ of Ophthalmology, Padjadjaran \\ University, Jawa Barat, ${ }^{4}$ Cicendo \\ Eye Hospital, Bandung, Indonesia; \\ ${ }^{5}$ Department of Ophthalmology, \\ G Gennimatas General Hospital, \\ University of Athens, ${ }^{6}$ Athens Retina \\ Institute, Athens, Greece
}

Background: To report the learning curve of transition from 20-gauge (20 G) conventional vitrectomy to a $20 \mathrm{G}$ sutureless vitrectomy technique.

Materials and methods: This is a retrospective descriptive case study of 32 eyes from 32 consecutive patients who underwent sutureless $20 \mathrm{G}$ pars plana vitrectomy. A $20 \mathrm{G}$ microvitreoretinal blade was introduced, beveled transconjunctivally, slowly, parallel with the limbus, creating a conjunctivoscleral tunnel incision. Study participants were divided into three groups, and surgical time, induced astigmatism, and complications were compared.

Results: Of 32 consecutive patients, there was no significant difference in induced astigmatism or maneuvering between the early learning curve and other groups. The true learning curve was the first three patients. There were three cases where suturing the sclerotomy was necessary: one port in each case, three of 32 cases $(9.3 \%)$, or three of 96 ports $(2.9 \%)$.

Conclusion: There were no significant difficulties in surgical maneuvers while performing 20 g sutureless vitrectomy.

Keywords: sutureless, vitrectomy, 20 G, learning curve

\section{Introduction}

Since Machemer et al invented closed intraocular microsurgery in 1971, ${ }^{1}$ the practice of pars plana vitrectomy using 20-gauge vitrectomy instruments through the sclera, following incision of the conjunctiva, has been the standard procedure for decades. However, there are a number of problems associated with $20 \mathrm{G}$ vitrectomy, such as iatrogenic retinal breaks, particularly those associated with sclerotomies, and the extra time required to create and suture the sclerotomies. Therefore, sutureless transconjunctival vitrectomy (TCV) was developed aimed at several advantages, such as less time required to create the sclerotomies, less postoperative inflammation, less operative corneal change, and faster recovery. ${ }^{2-4}$

Fujii et al introduced $25 \mathrm{G} \mathrm{TCV}$, which allowed smaller sclerotomies that were thought to reduce surgically induced trauma. ${ }^{5,6}$ Eckardt then developed $23 \mathrm{G}$ TCV to combine the minimally invasive TCV with the benefits of sturdier, larger instruments for more complex maneuvers. ${ }^{7}$ Moreover, the recently developed 27 G TCV by Oshima et $\mathrm{al}^{8}$ promised more safety from wound leakage and endophthalmitis. Despite the advantages, these small-gauge instruments may also have some disadvantages, such as the increased flexibility of the smaller instruments, breakage of fragile instruments, small vitrector port size, and an initial learning curve in wound construction. These inventions also involve higher cost in purchasing new equipment for performing $23 \mathrm{G}, 25 \mathrm{G}$, and $27 \mathrm{G}$ vitrectomy, since these procedures require additional specially designed intraocular instruments other than the ones required for conventional $20 \mathrm{G}$ vitrectomy.
Correspondence: Gilbert WS Simanjuntak Department of Ophthalmology, Christian University of Indonesia, Jalan Sutoyo PS Cawang, Jakarta I3630, Indonesia

Tel +62811168237

Fax +62 21 38997778

Email retinaid@yahoo.com 
A $20 \mathrm{G}$ transconjunctival technique using standard instrumentation without wound sutures has recently been introduced, with promising results. ${ }^{9,10}$ This technique has the advantages of a small-port TCV system without the necessity of new instrumentation other than the $20 \mathrm{G}$ standard. This technique also has other $20 \mathrm{G}$ advantages, including efficient surgery time and instrument rigidity. However, using sutureless $20 \mathrm{G}$ system requires a learning curve, since this technique has a different approach compared with ordinary $23 \mathrm{G}$ or $25 \mathrm{G}$ systems that are commercially available.

In this study, we report our experience of the use of $20 \mathrm{G} \mathrm{TCV}$ in order to assess the efficiency and reliability of this surgical technique, including the transition from the conventional to the sutureless system.

\section{Materials and methods}

The study was done at the Department of Ophthalmology, Christian University of Indonesia/Cikini Church Hospital, Jakarta, Indonesia. Informed consent was obtained from the study participants, and conducted following the tenets of the Declaration of Helsinki. The Christian University of Indonesia Institutional Review Board granted approval for this study. This was a descriptive study. The inclusion criteria were patients vitrectomized with a transconjunctival sutureless $20 \mathrm{G}$ technique. Patients with opened and sutured conjunctiva (patient with encircling band, etc) were excluded from the study. Sutureless $20 \mathrm{G} \mathrm{TCV}$ was performed in all patients; intra- and postoperative complications were documented. The surgical technique was learned through a recorded operation described by Gotzaridis. ${ }^{10}$

\section{Surgical technique}

The technique begins with heavy diathermy of the conjunctiva using a short-neck wide-tip diathermy probe over the areas of the side ports. The diathermy of the conjunctiva is broad and intense, so as to prevent leakage of intraocular fluid into the subconjunctiva. The probe presses and stretches the conjunctiva over the sclera. The conjunctiva becomes thin or very thin, and sometimes creates an opening with a gradually thinning rim that is sealed with the underlying sclera. The visible end point of the conjunctival burn is a white circle, the size of which must be large enough (4-5 mm diameter).

A conjunctivoscleral tunnel was performed simply by puncturing at the diathermized conjunctiva, making the tunnel as long as possible, parallel with the limbus; a $20 \mathrm{G}$ microvitreoretinal blade was introduced and beveled slowly parallel with the limbus, creating a conjunctivoscleral tunnel incision. The blade was then directed vertically toward the optic nerve, as the surgeon felt no resistance, to create a better wound sealing at the end of the operation. A $6 \mathrm{~mm}$ cannula was used in this port without a suture. Superotemporal and superonasal conjunctivosclerostomies were then done with a similar technique. Since our chandelier light pipe (DORC, Zuidland, the Netherlands) was easier to penetrate through the port, it was introduced first through the cutter port, just to open the wound, to facilitate introducing the cutter intraocularly.

Unnecessary exchange of the instrument through the sclera tunnels was avoided to prevent enlargement of the ports and unnecessary wound leakage. Vitrectomy procedures were performed for all spectra of retinal cases. All vitreous tamponades were used as per indication. At the end of the operation, intraocular pressure was normalized by tamponade injection if low or aspiration if too high. Immediate massage with a cotton tip over the port allowed sealing of the wound. To ensure no leakage, especially in an air/gas-filled eye, fluid was dropped on the wound to check the air bubble at the end of the surgical procedure. In cases where hypotony was noted by digital press onto the eyeball, additional $\mathrm{SF}_{6} 20 \%$ gas or fluid was injected through the pars plana with a $26 \mathrm{G}$ needle.

Whenever the surgeon was not sure about the sealing of the port, the wound was sutured with 8-0 Vicryl ${ }^{\circledR}$ (Johnson \& Johnson, New Brunswick, NJ, USA). Subconjunctival injections of antibiotics and corticosteroids were used at the end of the procedure. Overall, the surgical technique was similar to the one previously reported, ${ }^{10}$ but this study focused on the learning curve without the guidance of an experienced surgeon.

Automated keratometry (RC-5000; Tomey, Nagoya, Japan) was done preoperatively (K1) and day 7 postoperatively (K2). Intraocular pressure was measured preoperatively and on days 1 and 3 postoperatively. Surgical time was counted after the placement of the speculum and the grasping of the conjunctiva at the beginning of surgery (T1), and while closing the wound (T2), after the whole intraocular procedure was performed. The sum of T1 and T2 was total time (T3). Healing and inflammation were evaluated at 3 weeks postoperatively. Patients were followed up for at least 6 months. All subjects were divided into three groups (ten or more subjects per group) in order to see any difference between learning curves. SPSS version 13.0 (SPSS, Chicago, 
IL, USA) was used for all statistical analysis, and $P<0.05$ was considered significant.

\section{Results}

We studied 32 eyes from 32 consecutive patients who underwent pars plana vitrectomy performed by a single surgeon (GWSS). Surgery was performed under local anesthesia with $2 \mathrm{~mL}$ lidocaine $2 \%$ and $3 \mathrm{~mL}$ bupivacaine. Conjunctival diathermy was performed until the conjunctiva appeared attached on the sclera below. The attached conjunctiva was seen as a marked white area, and subtle blood vessels were seen. Where a thick Tenon's capsule was seen, it required longer diathermy until the conjunctiva attached to the sclera. As far as the creation of the conjunctivoscleral tunnel was concerned, some patients had thinner sclera than others, and a scleral tunnel was achieved more easily. Since the direction was parallel with the limbus, forcing too much could possibly cause double penetration; therefore, insertion was performed slowly and the blade directed toward the optic nerve once we believed that the blade was intraocular.

The surgeon observed no difficulties while performing vitrectomy, and all surgical maneuvers were done similarly to conventional $20 \mathrm{G}$ vitrectomy. There was no need for additional instruments during the transition to the sutureless technique and/or during vitrectomy procedures. There was only a slight difficulty while introducing the instruments initially through the conjunctivoscleral tunnels.

Of the 32 consecutive patients who underwent vitrectomy with the described technique, the duration of surgery was measured with video recording for the first two cases, and the rest measured during surgery. The study started from the third case using the technique, and the first two recorded cases
Table I Demographics of the patients $(n=32)$

\begin{tabular}{lll}
\hline Sex & Male & $15(46.9 \%)$ \\
Age (years) & Female & $17(53.1 \%)$ \\
Diagnosis & & $54.69(28-72)$ \\
& PDR/VH/TRD & $10(32 \%)$ \\
& Rhegmatogenous RD & $7(22.4 \%)$ \\
& Vein occlusion & $4(12.8 \%)$ \\
& Macular hole & $3(9.6 \%)$ \\
& Macular pucker & $3(9.6 \%)$ \\
Systemic disease & Others & $5(16 \%)$ \\
& DM & $12(38.2 \%)$ \\
& Hypertension & $7(22.4 \%)$ \\
\hline
\end{tabular}

Abbreviations: PDR, proliferative diabetic retinopathy; $\mathrm{VH}$, vitreous hemorrhage; TRD, tractional retinal detachment; RD, retinal detachment; $D M$, diabetes mellitus.

were included to avoid bias of the learning curve. Distribution between sexes was equal between male and female. The procedure was done for all spectra of retinal surgical surgery. Demographics of the patients are shown in Table 1.

As far as induced astigmatism is concerned, there was no significant difference between the early learning curve (group 1 consisting of ten patients) with other groups. Similarly, there was no difference when comparing the time required to make a sclerotomy (T1) and closing sclerotomy (sutureless [T2]). The only significant difference was total time (sum of $\mathrm{T} 1+\mathrm{T} 2$ ) between group 1 and group $2-0.97$ minutes (Table 2) - and there was no difference between groups 2 and 3. It was shown that actually the true learning curve comprised the first three patients in group 1, and the rest of the cases needed almost similar total time (Figures 1 and 2).

There were three cases where the scleral port had to be sutured: one port in each case, three of 32 cases $(9.3 \%)$ or three of 96 ports $(2.9 \%)$. The first two sutured

Table 2 Induced astigmatism and surgical time of consecutive surgery

\begin{tabular}{|c|c|c|c|c|}
\hline Variable & Group & Mean \pm SD & $P$-value & $\mathrm{Cl}$ \\
\hline \multirow[t]{3}{*}{ Induced astigmatism } & $I(n=10)$ & $0.44 \pm 0.39$ & & \\
\hline & $2(n=10)$ & $0.34 \pm 0.18$ & 0.45 & -0.18 to 0.39 \\
\hline & $3(n=12)$ & $0.4 I \pm 0.29$ & 0.52 & -0.29 to 0.15 \\
\hline \multirow[t]{3}{*}{ Sclerotomy time (minutes) $(\mathrm{TI})$} & $I(n=10)$ & $2.58 \pm 0.38$ & & \\
\hline & $2(n=10)$ & $2.35 \pm 0.14$ & 0.08 & -0.04 to 0.50 \\
\hline & $3(n=12)$ & $2.35 \pm 0.10$ & 1.00 & -0.10 to 0.10 \\
\hline Closing sclerotomy & $I(n=10)$ & $3.8 I \pm 1.26$ & & \\
\hline \multirow[t]{2}{*}{ Time (minutes) (T2) } & $2(n=10)$ & $3.07 \pm 0.17$ & 0.08 & -0.13 to 1.61 \\
\hline & $3(n=12)$ & $3.3 I \pm 0.83$ & 0.37 & -0.81 to 0.31 \\
\hline \multirow[t]{3}{*}{ Total time (minutes) (T3) } & $I(n=10)$ & $6.39 \pm 1.28$ & & \\
\hline & $2(n=10)$ & $5.42 \pm 0.25$ & 0.04 & 0.04 to 1.90 \\
\hline & $3(n=12)$ & $5.67 \pm 0.81$ & 0.37 & -0.80 to 0.31 \\
\hline
\end{tabular}

Abbreviations: SD, standard deviation; $\mathrm{Cl}$, confidence interval. 


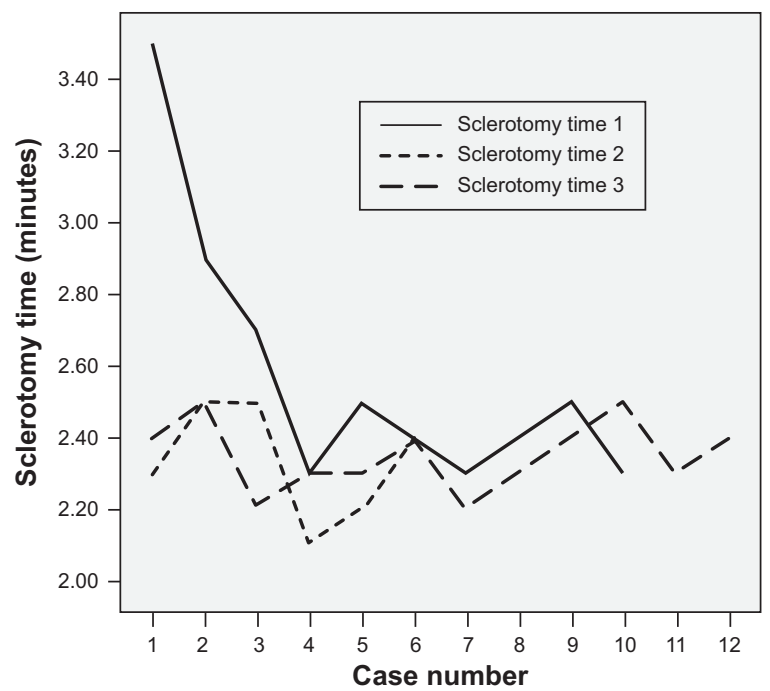

Figure I Time required for sclerotomy.

ports (cases 6 and 10) occurred in the first group of cases (group 1) and the third (case 25) probably occurred due to the frequent insertion and removal of the instruments while doing membrane peeling, which induced irregularity in the sclerotomy.

There was one case of ballooning of the conjunctiva during vitrectomy, which obscured the port. In that case, the conjunctiva was then incised and drained, but at the end of surgery the port was self-sealing. The intraocular pressure of the eyes at the end of the operation was either normal or slightly low. No choroidal detachment, hypotony, hypotonic

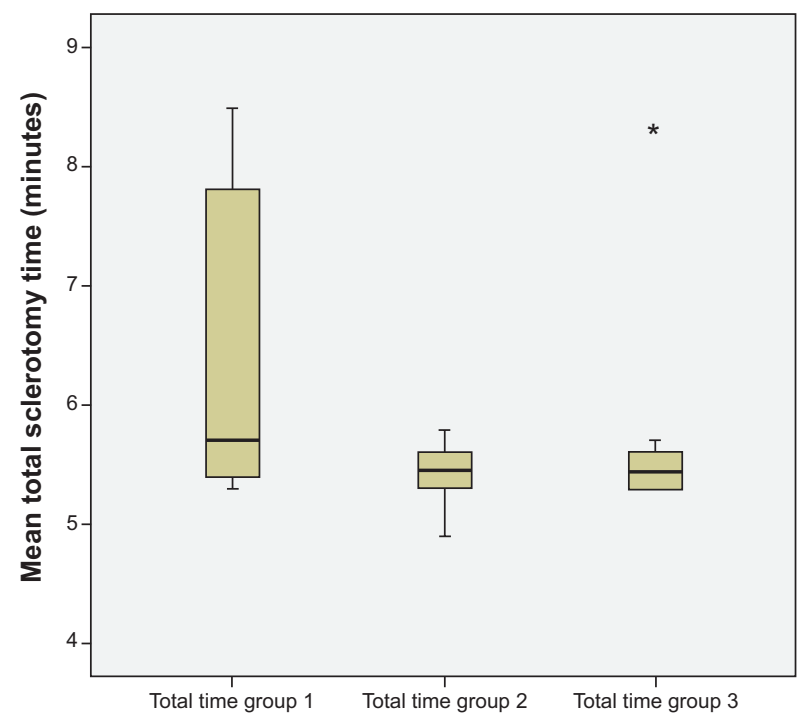

Figure 2 Total surgical time in each learning-curve group.

Note: $*$ A case from group 3 where the surgical time was longer than the mean time in that group. maculopathy, endophthalmitis, or other complications were observed during the postoperative period caused by hypotony or by wound leakage from the scleral ports. There was no compromised illumination, and cutting was as convenient as in conventional $20 \mathrm{G}$ vitrectomy.

\section{Discussion}

In recent years, sutureless vitrectomy has become more and more popular to vitreoretinal surgeons. The advantages of sutureless surgery include minimization of ocular trauma and suture-induced astigmatism, as well as the fact that postoperative inflammation is less in the operated eyes. However, small-gauge sutureless vitrectomy systems may sometimes not be available or suitable, especially for complex cases. Disadvantages of $23 \mathrm{G}$ and $25 \mathrm{G}$ vitrectomy include prolonged surgical time during vitrectomy, as well as increased flexibility of the smaller instruments, which may be a disadvantage in more demanding cases. ${ }^{9-11}$ Additionally, slow vitreous removal and dim illumination are problems with $25 \mathrm{G}$ or $23 \mathrm{G}$ technology at present, which can be addressed by new vitrectomy machines, but with more expensive equipment and consumables.

Small-gauge vitrectomy may require new modified instruments that may not always be available. Therefore, using a $20 \mathrm{G}$ sutureless procedure may be an interesting alternative, combining the advantages of sutureless vitrectomy on the one hand, and on the other, the advantages of $20 \mathrm{G}$ instruments, such as reduced surgical time and no necessity for new and more expensive instruments.

The transition from conventional $20 \mathrm{G}$ to $20 \mathrm{G}$ sutureless vitrectomy includes a learning curve to achieve maximum efficiency. In our results, the learning curve was short enough for the adaptable surgeon. Despite the significant difference between the early learning curve (group 1) to the next group, a clinical time difference of 0.97 minutes between groups 1 and 2 means less for the total surgical time of vitrectomy that may sometimes take 1-3 hours (Table 2). The only difference of the sutureless technique compared to vitrectomy with a conventional port is while structuring and closing the sclerotomies. The vitrectomy procedure is similar, without the need for modification of the technique or a long transition period for the surgeon. There is no compromise in the intraoperative illumination either, and cutting is faster in comparison with smaller-gauge vitrectomy machines.

For the surgeon accustomed to performing $20 \mathrm{G}$ vitrectomy, the transition is easy. The rigidity of the instruments 
and flow and aspiration of the vitreous cutter is comfortable. The construction of the incision must be meticulous, using tunnel or angled incision to reduce postoperative hypotony.

Wound architecture is the most important aspect of this surgery, and the hardest thing for the surgeon to learn, and may be followed by hypotony and potentially increase such complications as endophthalmitis and hypotonic maculopathy. However, the learning curve is short enough for the adaptable surgeon. In conclusion, $20 \mathrm{G} \mathrm{TCV}$ through a single-step entry cannula system is a relatively safe procedure, allowing the use of stiff $20 \mathrm{G}$ instruments that are particularly valuable in more challenging cases requiring more manipulations. Also, it offers an economic advantage to surgeons to use the existing $20 \mathrm{G}$ instrumentation. When suturing was required, a single transconjunctival absorbable stitch postoperatively was adequate. Our initial experience shows that although approximately a third of the sclerotomies were sutured, this procedure may be an alternative option to vitreoretinal surgeons interested in a transconjunctival approach to vitrectomy. Further studies are required to confirm our findings and to investigate the differences between trocar and trocarless vitrectomy, something that was not addressed in our study.

\section{Disclosure}

The authors report no conflicts of interest in this work.

\section{References}

1. Machemer R, Buettner H, Norton EW, Parel JM. Vitrectomy: a pars plana approach. Trans Am Acad Ophthalmol Otolaryngol. 1971; $75: 813-820$.

2. Kadonosono K, Yamakawa T, Uchio E, Yanagi Y, Tamaki Y, Araie M. Comparison of visual function after epiretinal membrane removal by 20-gauge and 25-gauge vitrectomy. Am J Ophthalmol. 2006; 142:513-515.

3. Yanyali A, Celik E, Horozoglu F, Oner S, Nohutcu AF. 25-gauge transconjunctival sutureless pars plana vitrectomy. Eur J Ophthalmol. 2006;16:141-147.

4. Yanyali A, Celik E, Horozoglu F, Nohutcu AF. Corneal topographic changes after transconjunctival (25-gauge) sutureless vitrectomy. Am J Ophthalmol. 2005;140:939-941.

5. Fujii GY, De Juan E Jr, Humayun MS, et al. A new 25-gauge instrument system for transconjunctival sutureless vitrectomy surgery. Ophthalmology. 2002;109:1807-1812; discussion 1813.

6. Fujii GY, De Juan E Jr, Humayun MS, et al. Initial experience using the transconjunctival sutureless vitrectomy system for vitreoretinal surgery. Ophthalmology. 2002;109:1814-1820.

7. Eckardt C. Transconjunctival sutureless 23 -gauge vitrectomy. Retina 2005;25:208-211.

8. Oshima Y, Wakabayashi T, Sato T, Ohji M, Tano Y. A 27-gauge instrument system for transconjunctival sutureless microincision vitrectomy surgery. Ophthalmology. 2010;117:93-102.e2.

9. Lee JE, Kim KH, Kim IK, Jea SY, Kim WS. Comparison of 20-gauge transconjunctival sutureless vitrectomy with conventional vitrectomy. Retina. 2010;30:1496-1504.

10. Gotzaridis EV. Sutureless transconjunctival 20-gauge pars plana vitrectomy. Semin Ophthalmol. 2007;22:179-183.

11. Kim JE, Shah SN, Choi DL, Han DP, Connor TB. Transconjunctival 20 -gauge pars plana vitrectomy using a single entry cannulated sutureless system. Retina. 2009;29:1294-1298.
Clinical Ophthalmology

\section{Publish your work in this journal}

Clinical Ophthalmology is an international, peer-reviewed journal covering all subspecialties within ophthalmology. Key topics include: Optometry; Visual science; Pharmacology and drug therapy in eye diseases; Basic Sciences; Primary and Secondary eye care; Patient Safety and Quality of Care Improvements. This journal is indexed on

Submit your manuscript here: http://www.dovepress.com/clinical-ophthalmology-journal

\section{Dovepress}

PubMed Central and CAS, and is the official journal of The Society of Clinical Ophthalmology (SCO). The manuscript management system is completely online and includes a very quick and fair peer-review system, which is all easy to use. Visit http://www.dovepress.com/ testimonials.php to read real quotes from published authors. 